\title{
CONCRETE SAWING WASTE RECYCLING AS MICROFILLER IN CONCRETE PRODUCTION
}

\author{
G.Bumanis, G.Shakhmenko, P.Kara, A.Korjakins \\ Riga Technical University, Institute of Materials and Structures, \\ Department of Building Materials and Units \\ 1 Kalku str., LV 1658, Riga, Latvia \\ Ph.: +(371)29160832, fax: +(371)67089248, e-mail: gs@apollo.lv
}

\begin{abstract}
The main idea of the presented work is to find the ways of recycling the sawing waste/sludge in production of the new concrete. The aim of the study is to examine application of the dust-water suspension as micro filler in self-compacting concrete. In the process of sawing concrete elements a lot of dust waste is produced, the average amount being approximately 0.5-1\% of the total amount of concrete. To avoid dust pollution in a production plant the sawing process is accompanied by a water stream, as a result, concrete dust as dust-water suspension is stored in special reservoirs. Recycling of such concrete dust suspension and its utilization as a material pose a significant challenge.
\end{abstract}

Keywords: concrete sawing waste, sludge water, compressive strength.

\section{Introduction}

A lot of concrete waste is produced in the process of sawing concrete elements in the plants that manufacture pre-cast reinforced concrete. Technologically the process of sawing is accompanied by a water stream to avoid dust pollution and enhance sawing efficiency. Concrete saw waste (that is called sludge) is stored in special reservoirs for further utilization. The average amount of produced waste is about $0.5-1 \%$ of the total amount of concrete. The information about utilization of the saw sludge is pretty scarce; with the increasing volumes of concrete production it is turning into a serious environmental issue. The information, which is generally available, is about the waste water and water sludge containing residual cement from concrete mixing plants and agitator trucks $[1,2]$. Usually waste water is divided into two fractions as shown in Figure 1; one is a relatively clean fraction and it is called clarified water, whereas the other one is sludge water containing cement solids and other fine concrete particles. Clarified water can be used as mixing water in new batches, thus replacing some part of the water from town water supply sources. Due to the large amount of suspended matter and high alkalinity untreated sludge water cannot be legally discharged into urban sewers (Borger et al., 1994). It is stated in standard that the amount of the solid content in sludge water should contain less than $3 \%$ of cement content by weight, when used as mixing water. The sludge water with $3 \%$ of sludge solid content ratio can be used up as mixing water if the constant amount of ready-mixed concrete is produced every day [3]. However, since the ready-mixed concrete is an order-made product, fine particles in unused sludge water settle out. The settled material is usually dehydrated, and this is called sludge cake. Most of the sludge cake is discharged to the controlled landfills, because the settled material falls under the category of dirty mud according to standard. The total disposal cost of sludge cake is very high [3]. With the growing demand for ready mixed concrete, the disposal of sludge water is becoming an increasing environmental concern $[4,5]$. Each working day approximately 700 13001 of wash water is required for a single concrete truck [6]. Since it is very difficult to treat the sludge cake as concrete material because of its high water content (70\% by weight), the process of drying and crushing is introduced to make pulverized dry sludge from the sludge cake. Significant challenge is to recycle this concrete dust suspension with $95 \%$ of particles smaller than $0,063 \mathrm{~mm}$, and some with size $<2 \mathrm{~mm}$ and use it as a material. 
It has been found that fine-filler effects and a reduction of the actual water/cement ratio due to the fine solids content of sludge water lead to a reduction in concrete capillary water absorption and porosity, and possibly improve the durability of the concrete [6].

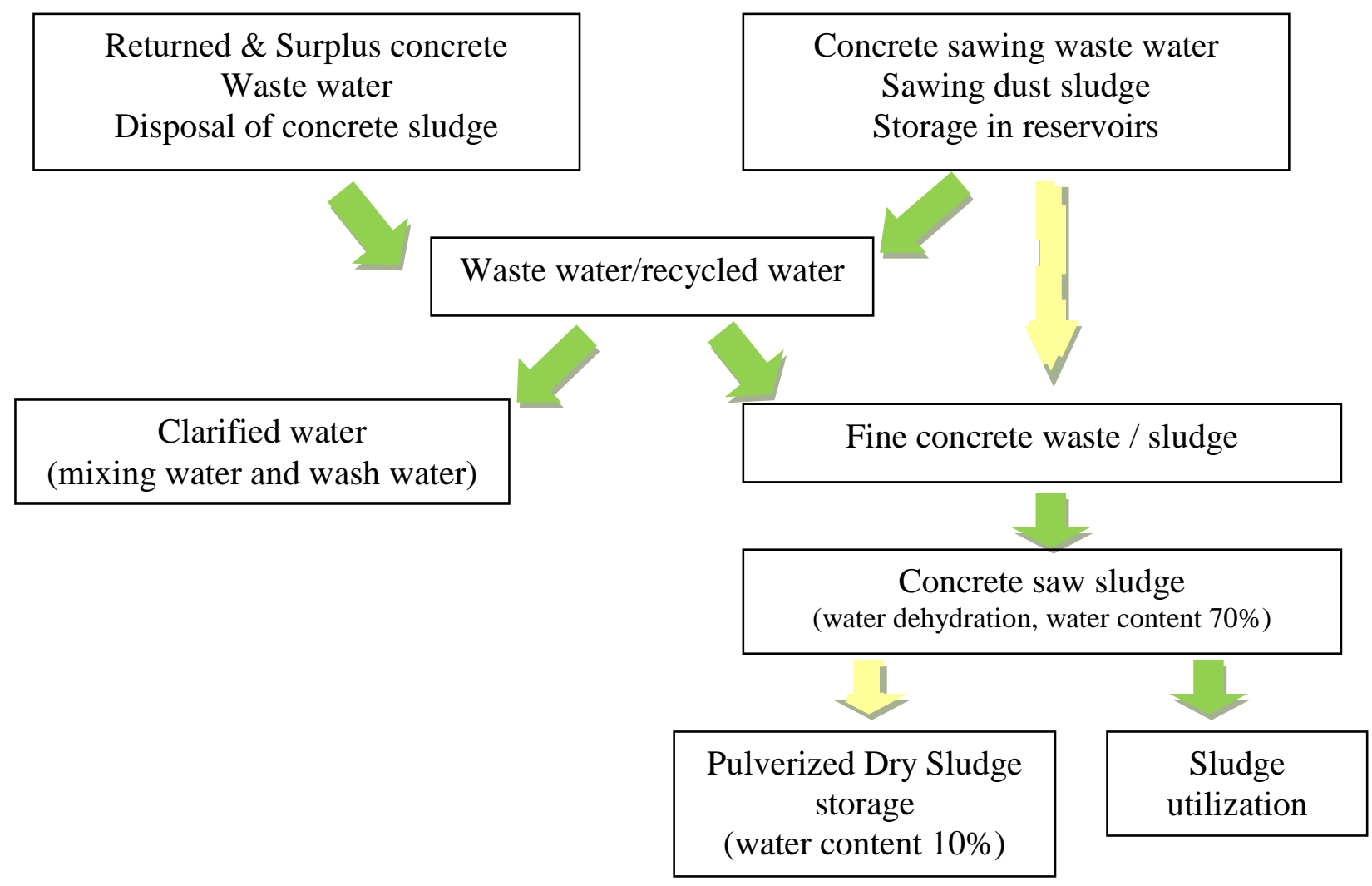

Fig. 1. Effective use of concrete sludge

Concrete mixed with the sludge water containing residual cement tends to exhibit a shorter setting time and lower flowability [7]. Nevertheless, the complete recycling of sludge water has been considered in concrete mixing plants because of the great benefit in terms of disposal cost reduction and environmental conservation $[7,8,9]$.

It is necessary to investigate strategies for managing the effective use of concrete sludge. The main idea of the presented work is to find the ways of recycling concrete sawing waste sludge in production of the new concrete. The material used in mixes is sludge water suspension originally taken from the source in a concrete plant to avoid additional costs of material drying and grinding. Ways of how to utilize sludge water in mixes containing both an additive and an admixture will be researched in the future.

\section{Basic properties of concrete saw sludge (SL)}

\section{Materials and methods}

Material used in this research is a waste by-product saw sludge from a pre-cast reinforced concrete plant which needs an efficient way of recycling. Proper use of this waste would prevent landfills from further storage of this kind of waste. Samples of concrete sawing sludge (SL) for experimental work were collected at a pre-cast concrete plant. The origin of the waste material is the sawing sludge created during cutting of the hardened reinforced concrete panels with the help of the diamond disc with the stream of water. The waste thus obtained represents fine concrete particles suspension, which consistency is that of a paste. 
The following basic characteristics of the sawing sludge were determined:

Moisture (water) content:

Dry material content:

Sludge bulk density:

Dry particle density:
$70 \%$ of the mass (deviations $69-71 \%$ )

$30 \%$ of the mass

$1240 \mathrm{~kg} / \mathrm{m}^{3}$

$2650 \mathrm{~kg} / \mathrm{m}^{3}$

Amount of particles smaller than $0.063 \mathrm{~mm}: 98 \%$

Particle grading analysis was performed with the help of laser diffraction in water environment. The results indicated the presence of fine particles with a wide size range: 0.3 $50 \mu \mathrm{m}$ (Fig. 2), the average particle diameter being $8.3 \mu \mathrm{m}$.

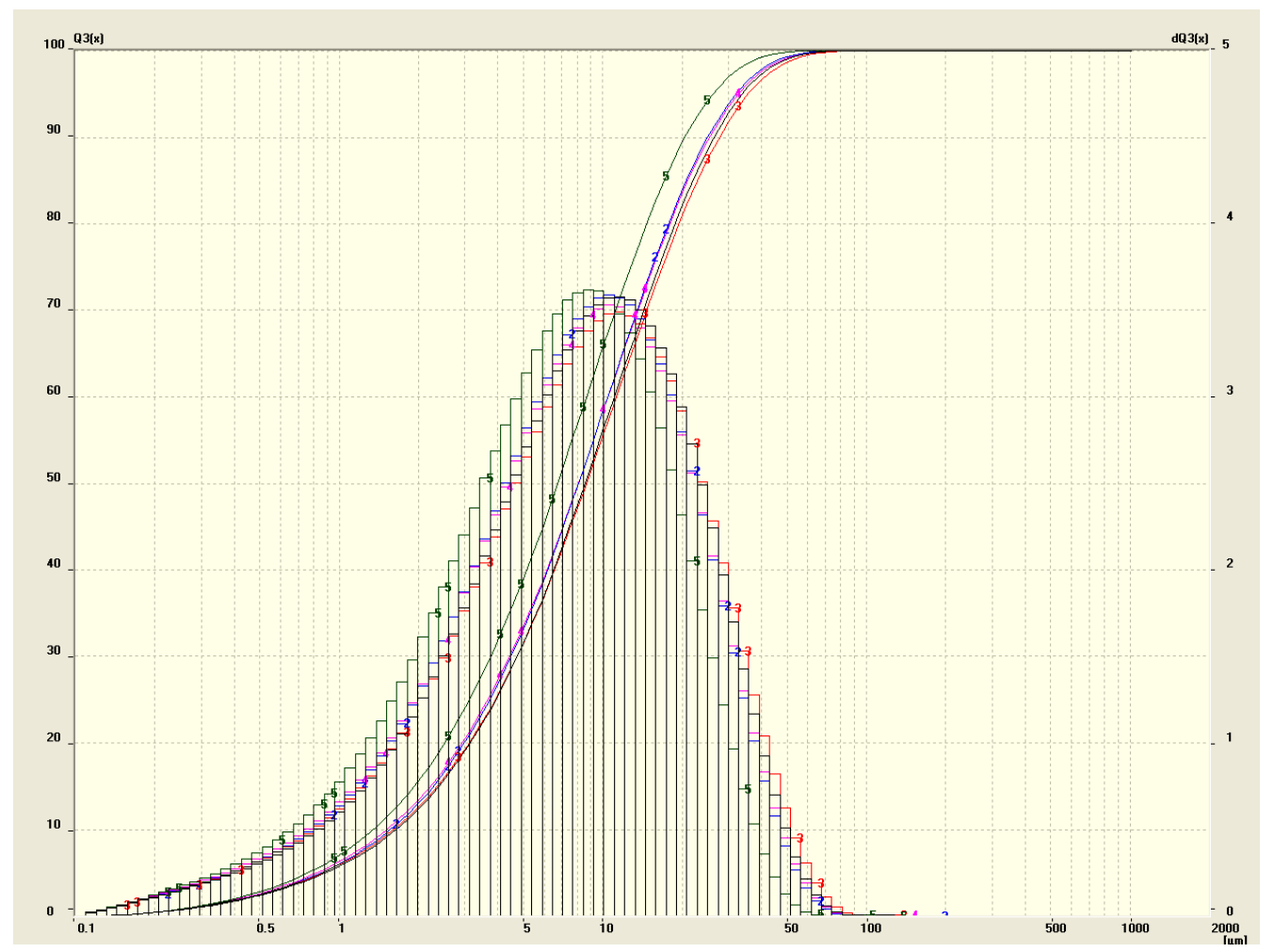

Fig.2. Particle size distribution diagram (by laser diffraction method)

\section{Experimental methods}

During the experiment self-compacting concrete (SCC) with various amounts of cement and micro fillers was produced in the laboratory. Local commercially available materials were used as fine and course aggregates. Dolomite powders (D), silica fume (SF) and concrete saw sludge (SL) were used as micro fillers.

Concrete components were batched and then mixed in the laboratory drum mixer during 4 minutes. For examination of the material properties standard testing sample $100 \times 100 \times 100 \mathrm{~mm}$ cubes were produced. Concrete mixtures were cast into the oiled steel moulds without vibrating. Two days later the samples were dismantled. Standard curing conditions (temperature $20 \pm 2^{\circ} \mathrm{C}, \mathrm{RH}>95 \pm 5 \%$ ) were provided during the process of hardening. Sample compressive testing was performed after the 3,7 and 28-days ageing period. Compression testing machine with the accuracy of $\pm 1 \%$ was used, the rate of loading was $0.7 \mathrm{MPa} / \mathrm{sec}$ (according to LVS EN 12390-3:2002 standard).

Modern methods of mix workability testing such as cone flow and V-funnel methods were applied. Compressive strength of the concrete was obtained after 2, 7 and 28 days of standard curing period [10-14]. Water absorption tests were carried out. 


\section{Mix compositions}

\section{Results and discussion}

During the first stage of experimental work three SCC mixes with the cement content 360 $\mathrm{kg} / \mathrm{m}^{3}$ were prepared. Mix SF-1 contained silica fume as micro filler. D mix contained dolomite powder. Mix SL-1 contained only concrete sludge as micro filler, with the same content of fine particles that was recalculated to dry powder. Concrete sludge waste was used as dust/water suspension paste.

During the second stage of experimental mixing high strength SCC mixes with cement content $450 \mathrm{~kg} / \mathrm{m}^{3}$ were produced. Mix SF-2 and SL-2 contained silica fume and saw sludge paste accordingly as micro fillers. Mix 50/50 was created with silica fume being dispersed in water-sludge suspension in the proportion $1 / 1$ to dry material. Compositions of the mixes and properties of fresh concrete mixes are summarized in Table 2.

\section{Mix compositions and properties of fresh concrete (cement content $360 \mathrm{~kg} / \mathrm{m}^{3}$ )}

Table 2.

\begin{tabular}{|l|c|c|c|}
\hline \multicolumn{1}{|c|}{ Mix composition: } & SF-1 & D & SL-1 \\
\hline Portland cement I CEM 42.5 N & \multicolumn{3}{|c|}{360} \\
\hline Gravel 2/8mm & \multicolumn{3}{|c|}{450} \\
\hline Gravel 8/16mm & \multicolumn{3}{|c|}{450} \\
\hline Sand 0/2mm & 60 & & \\
\hline Silica fume & & 60 & \\
\hline Dolomite powder & & & 200 \\
\hline $\begin{array}{l}\text { Saw sludge, moisture content } \\
70 \%\end{array}$ & & & 60 \\
\hline $\begin{array}{l}\text { Saw sludge, recalculated to dry } \\
\text { matter }\end{array}$ & 7.0 & 7.0 & 7.0 \\
\hline Super plasticizer & 193 & 187 & 204 \\
\hline Water, incl. sludge water & 0.54 & 0.52 & 0.57 \\
\hline Water / Cement ratio & &
\end{tabular}

\begin{tabular}{|c|c|c|}
\hline SF-2 & 50/50 & SL-2 \\
\hline \multicolumn{3}{|c|}{445} \\
\hline \multicolumn{3}{|c|}{410} \\
\hline \multicolumn{3}{|c|}{410} \\
\hline \multicolumn{3}{|c|}{790} \\
\hline 90 & 45 & \\
\hline & & \\
\hline & 150 & 300 \\
\hline & 45 & 90 \\
\hline 10 & 10 & 11 \\
\hline 190 & 201 & 233 \\
\hline 0.43 & 0.45 & 0.52 \\
\hline
\end{tabular}

Properties of fresh concrete:

\begin{tabular}{|l|c|c|c|}
\hline Cone flow, $\mathrm{mm}$ & 510 & 595 & 510 \\
\hline Time $500 \mathrm{~mm}, \mathrm{sec}$ & 3.7 & 3.2 & 3.4 \\
\hline V-funnel time, sec & 5.6 & 18.5 & 6.9 \\
\hline
\end{tabular}

Water dosage in concrete mixtures was selected in order to provide the required SCC concrete flowability through a flow cone (cone flow in the range $500 \ldots 600 \mathrm{~mm}$ ). The results of the experiment showed that concrete mixes with concrete saw sludge suspension used as micro filler require more water to achieve the fresh concrete properties that would be identical to the mixes with conventional micro fillers.

Compressive strength results of hardened concrete are summarized in Figure 3 and Figure 4. Results obtained for compressive strength indicate that SCC mix compositions filled with saw sludge (mix SL-1, SL-2) have the weakest strength properties. This phenomenon can be explained by the higher water content and higher value of water/cement ratio. Mixes with silica fume (mix SF-1, SF-2) have the highest compressive strength results; dolomite powder (D) recorded medium strength values.

The most interesting results were demonstrated by the 50/50 mix based on the composite micro filler containing $50 \%$ of silica fume and $50 \%$ of saw sludge fine particles. In 28 days, 
the compressive strength of that mix $(86.9 \mathrm{MPa})$ was just $8 \%$ lower in comparison to the mix with silica fume (92.3 MPa) and $27 \%$ higher in comparison to the mix SL-2 with saw sludge (68.3 MPa). This mix may become one of the prospective options for upcoming research. Such satisfactory results can be attributed to improved micro particle packing property resulting from such micro filler combination.

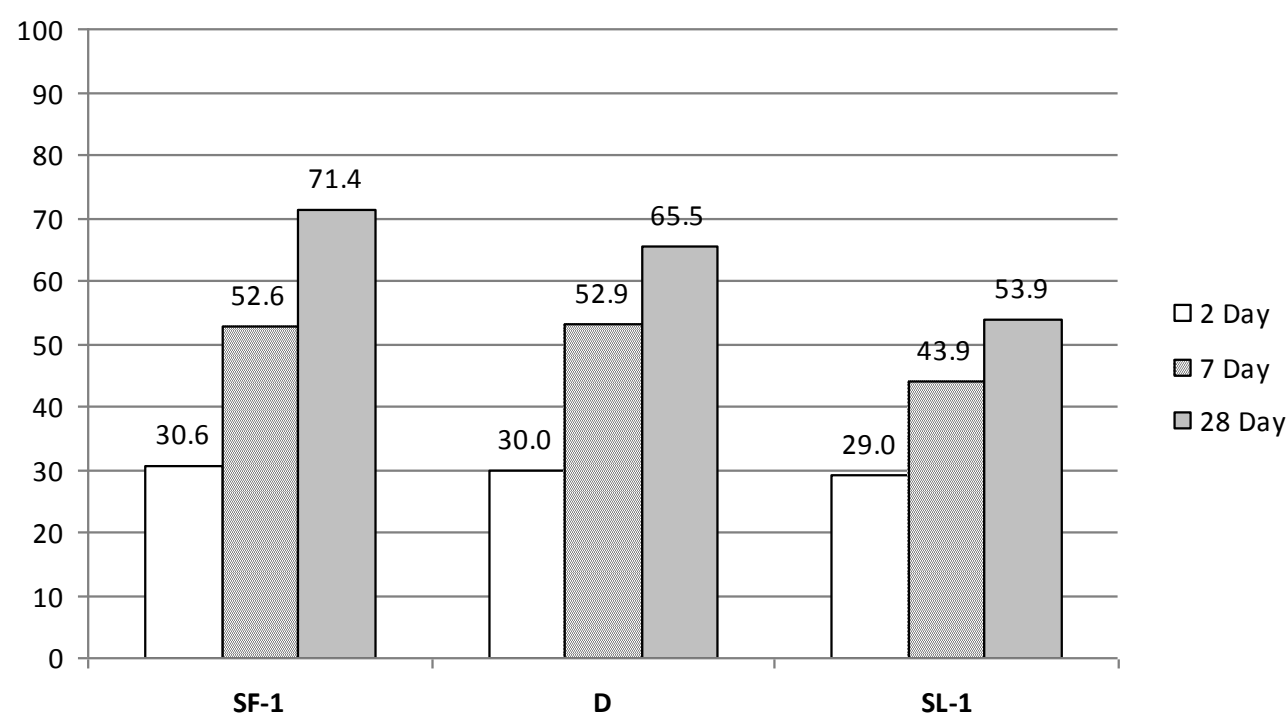

Fig.3. Compressive strength results (cement content $360 \mathrm{~kg} / \mathrm{m}^{3}$ )

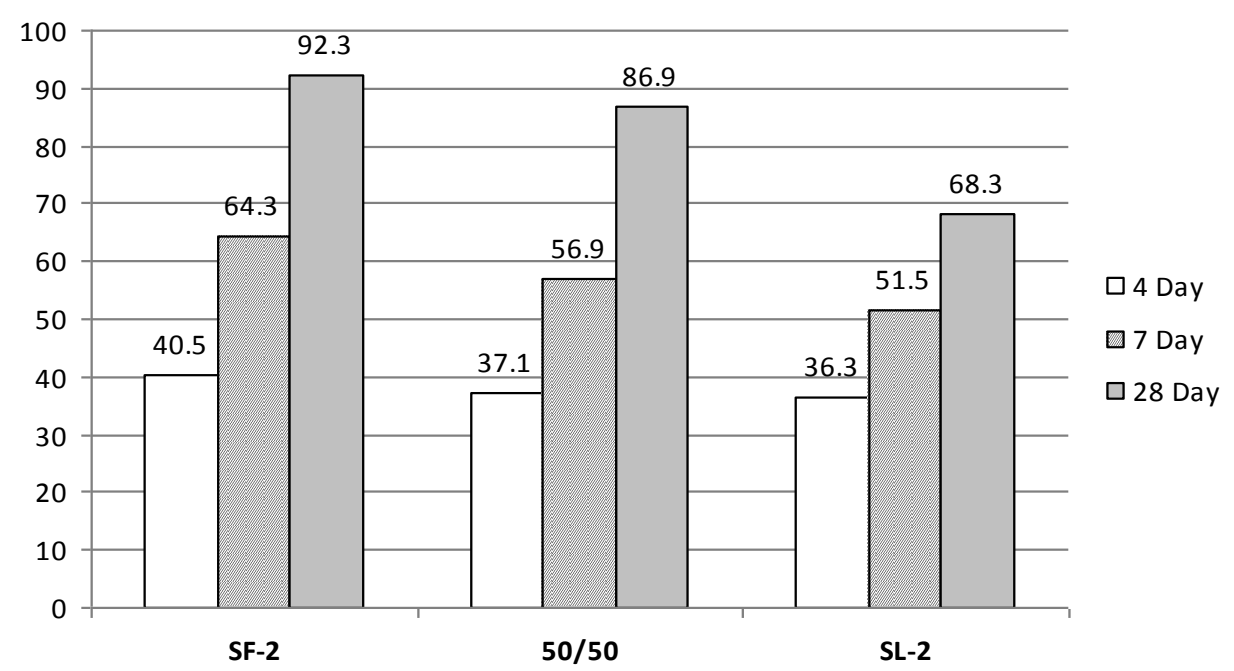

Fig.4. Compressive strength results (cement content $450 \mathrm{~kg} / \mathrm{m}^{3}$ )

Water absorption was determined for three concrete mixes containing $360 \mathrm{~kg}$ of cement. The results are as follows:

$\begin{array}{ll}\text { SF-1: } & 1.3 \% \\ \text { D: } & 3.8 \% \\ \text { SL-1: } & 4.3 \%\end{array}$

Mix with silica fume demonstrated the best result of $1.3 \%$, whereas dolomite and sludgefilled concrete samples have higher value: 3.8 and $4.3 \%$ accordingly. 


\section{Conclusions}

- Pilot SCC concrete mixes were made by adding concrete wet saw sludge as micro filler. The obtained results show lower physical and mechanical properties of the concrete compared to the mixes with silica fume and dolomite powder, as well as to the mixes with composite additives. Addition of wet sludge to concrete mix (without additional drying) significantly facilitates the use of sludge and provides good dispersion in concrete.

- Additional amount of water is required for the mixes with wet saw sludge to ensure concrete consistency of the mixes. Reduced compressive strength results (a decrease by $25 \%$ compared to silica fume mix) and increased water cement ratio were obtained. The mixes with silica fume showed lower water consumption, which corresponds to the data available in the literature, whereas higher water consumption results were demonstrated by the mixes made with wet saw sludge. This could be attributed to the angular shape of particles containing saw sludge.

- The mix with the combined micro filler 50/50 content (50\% silica fume and $50 \%$ of the sludge particles) looks prospective; it showed satisfactory results on strength given a relatively small quantity of micro fume. Research in this direction should be continued as it can provide the silica fume saving effect while the waste from precast concrete plants can be utilized.

- Further sludge research should be done. One of the prospective options of sludge waste disposal: conduct research of the conventional concrete properties with the smaller content of sludge waste in concrete in the range of $1-10 \%$ to cement weight. Another research that would involve combined micro fillers containing conventional fillers and sludge waste filler in various combinations should be performed either.

- In general view, concrete sludge waste could be re-used in concrete production to prevent environmental pollution and disposal to landfills. Apart from the ecological factor deterioration of concrete mechanical and physical properties should be taken into account in application of concrete sludge waste; the benefits of utilization of this waste material should be carefully assessed.

\section{Acknowledgement}

This study was funded by RTU ZP-2010/04 project "Recycling of concrete cutting waste as micro filler".

The authors would like to express appreciation to SIA Betonelements for the provided material - concrete saw sludge - which was used in experimental work.

\section{Summary}

Due to lack of information about utilization of concrete saw sludge worldwide and given the satisfactory results obtained in the present study, further investigation and research will be carried out in order to find feasible ways of recycling wastes from precast concrete plants.

\section{References}

1. Chatveera, B., Lertwattanaruk, P., Makul, N. Effect of sludge water from ready-mixed concrete plant on properties and durability of concrete. Cement and Concrete Composites 28, 2006, p. 441-450.

2. Chatveera, B., Lertwattanaruk, P. Use of ready-mixed concrete sludge water in concrete containing an additive or admixture, Journal of Environmental Management 90, 2009, p. 1901-1908.

3. Sato, Y., Kiyohara, C., Chia-Ming, L. Studies on the effective use of concrete sludge - sludge water and pulverized dry sludge, Exploiting wastes in concrete: seminar 5, 1999, p. 37-46

4. Borger, J., Carrdsguillo, R., Fowler, D. Use of Recycled Wash Water and Returned Plastic Concrete in the Production of Fresh Concrete, J. of Advanced Based Materials, 1994, p. 267-274

5. Souwerbren, C. Re-use of wash water in the concrete industrial production circle without waste. European standard for mixing water and the re-use of wash water, proc., of the Conf., Concrete in the service of mankind, concrete for environmental and protection, edited by R.K. Dhir \& T.D. Dyer, 1996, p.183-197 
6. Sandrolini, F., Franzoni, E. Waste wash water recycling in ready-mixed concrete plants. Cement and Concrete Research 31, 2001, p. 485-489.

7. Su, N., Miao, B., Liu, F. Effect of wash water and underground water on properties of concrete. Cement and Concrete Research 32, 2002, p. 777-782.

8. Chini, A.R., Muszynski, L.C. Reuse of wastewater at concrete plants in Florida in the production of fresh concrete. Magazine of Concrete Research 53 (5), 2001, p. 311-319.

9. Paolini, M., Khurana, R. Admixtures for recycling of waste concrete. Cement and Concrete Composites 20 , 1998, p. 221-229.

10. EN 12390-2:2002. Testing hardened concrete - Part: 2: Making and curing specimens for strength tests. LVS. Riga, 2002. 7 p.

11. EN 12390-3:2002. Testing hardened concrete - Part 3: Compressive strength of test specimens. LVS. Riga, 2002. 16 p.

12. Draft prEN 12350-8. Testing fresh concrete - Part 8: Self-compacting concrete - Slump-flow test. Brussels, 2007. 8 p.

13. Drafr prEN 12350-9. Testing fresh concrete - Part 9: Self-compacting concrete - V-funnel test. Brussels, 2007. $6 \mathrm{p}$.

14. 12730.3-78 "Бетоны. Метод определения водопоглощения" (Concretes. Method for determining water absorption) 